\title{
Renovating An Old Building For Cultural Use: A Study In Unreinforced Masonry
}

\author{
RICHARD EBELTOFT \\ University of Arizona \\ USA
}

\begin{abstract}
This paper examines the issue of renovation of buildings in the urban fabric of older central cities. It does so with a the case study of one such building. The building under study is a church that was originally constructed in the early 1900's and was in use into the eighties. Since then, building has been abandoned and fallen into disrepair. The building was renovated for use as a cultural arts and performance center for small user groups. It was an unreinforced masonry building with many structural defects that had to be overcome before any use could be made of the structure. The foundations in the basement were badly deteriorating. It had high spaces with tall unreinforced masonry walls and a truss roof that was in distress.

The thesis of the paper examines renovation issues beginning with the code requirements, building and structural techniques used to solve the problems from new loading requirements. The paper explores the differences in requirements for unreinforced structures in different seismic risk zones and looks at techniques to solve the various problems associated with these zones. It examines foundation stabilization and methods of accommodating additional loads. It also reviews methodologies for repair of physical distress in these masonry structures. The conclusion is one of the viability of such techniques and their probable degree of success.
\end{abstract}

\section{INTRODUCTION}

The advent of the automobile and the development of transportation corridors in this century have led to the flight of the more affluent segments of society from the city centers of America to the suburbs. Because of this change in demography, the urban centers of many cities in America have undergone a decline.

In the later part of this century as the cost of this urban blight has become more apparent, many cities have developed an interest in the renovation of these areas. In some cities deteriorated buildings were simple been torn down and replaced with new construction. With the appearance of the historic preservation movement, the recognition of the unique character of the old cityscape of these urban areas lead to a rethinking of this approach. The result was renovation of some of these areas rather than tearing down and rebuilding them.

These renovations face unique regional obstacles in different areas of the country. There are a large variety problems facing the task of this type, such as architectural performance, fire safety, transportation and economics, to name a few. One of the most significant is the issue of structural performance of these old buildings. They have performed their design functions with varying degrees of success for extended periods of time. However, as code requirements have advanced, building science improved and understanding of loading conditions such as seismic and wind have increased, the older buildings usually no longer meet current engineering criteria for building design.

The structural renovation of buildings has to addresses these issued to provide a building that is safe for its new intended use.

Tucson is not unlike many other western cities had such a central downtown area that once was the thriving center of the city. As discussed earlier the demography changed from a small central city to the typical American community with suburbs and new industrial and commercial centers developing in the outlying areas The businesses within the central city declined. This resulted in many buildings that were abandoned and left to deteriorate. In recent years there has been an effort by the local government, business and the community to give a rebirth to the old central area of the city by rehabilitating many of these buildings for new uses.

\section{OUTLINE OF PROBLEMS}

The Tucson community decided the best ways to redevelop the downtown district was the creation of an arts district at the center of the old city to help revitalize the area. To this end, a development corporation was formed to help advance this concept. As an initial project, one of the old performing arts theaters in this area was renovated and occupied by the local theater company. It proved to be very successful and was supported by the community. Subsequently because of 
the success of this theater, there was an interested in expanding this Arts District. To this end the development corporation of the City of Tucson decided to create a center where the myriad smaller performing arts groups in Tucson could come and practice their art and give performances. Within the same block as the theater there was an old church which had been abandoned and was deteriorating. It was decided to investigate this building to determine of it would be a feasible structure to renovate for this use.

The church was constructed in the early 1920 's and later modified in the 1940's. There were many structural problems that developed over the life of the structure. Also since this was a change of use for the building, the code required the building to be upgraded to current standards. The building was a single story structure with a basement. The upper space was a high open cruciform structure with low side halls typical of churches in that period.

The major existing structural problems with this building are outlined below.

- The building was an unreinforced brick masonry building in a 2 a seismic zone.

- The roof structure was a wood-steel truss structure which exhibited some structural distress.

- There were very limited connections from the roof to the walls.

- The exterior masonry walls were cracking in some locations.

- The floor system did not have adequate capacity for the gravity loads from the new theater loads.

- The basement walls were unreinforced rock walls with the mortar in the joints deteriorating.

There are several approaches to solving structural problems relating to existing buildings. One of these is to use a historic or modified code for the structural review, analysis and design. The strategy for approaching this building's problems was the adoption of the Uniform Code for Building Conservation $\{\mathrm{UCBC}\}$, which is a code designed for use in the renovation of older buildings. The UCBC attempts to set minimum reasonable standards for building safety that can be meet in

an economical manner and without destroying the historic fabric of the building. The UCBC, like the other building codes, sets different standards for buildings in different seismic risk zones. In general the lower the seismic risk zone the less the requirement for seismic upgrades. ${ }^{1}$

A proposal for the adoption of the UCBC was made to the Tucson Building Safety Department. They readily agreed that this was the appropriate strategy for renovating this building.

\section{FOUNDATION PROBLEMS}

The foundations and basement walls were distressed. The basement walls were a rock construction. Below grade the rocks were uncut natural shapes set together with a lime mortar. Above grade they were cut stone set with mortar up to the floor level. The existing roof drains were ejecting water next to the exterior of the basement walls. Over the years during the rainy seasons this area was periodically subject to partial saturation. Due to the repeated moisture penetration, the lime mortar deteriorated to the point the basement retaining walls were no longer a viable. Prior to this investigation, one portion of the North wall partially collapsed and was replaced with a reinforced masonry wall.

Several options were discussed for stabilizing the wall. For example various types of tie backs were considered. However, due to the large size of the rocks in the wall, the tie backs would have require drilling through the rocks and possibly removing some of the outside soil from the wall area. This option exposed the wall to excessive vibrations that, because of the poor condition of the mortar could destabilize the wall and possibly cause its' collapse. The basement wall was subject to a very large axial load because of the high masonry walls above. Consulting with the geotechnical engineer it was concluded that the vertical wall capacity would be adequate if we could contain the existing mortar in the wall and prevent further moisture penetration. It was necessary however to confine the mortar in the wall and to improve the lateral capacity.

It was decided that the most economical solution was the use of a cantilevere

$\mathrm{d}$ retaining wall, adjacent to the inside face of the basement wall, to provide the lateral restraint. This wall would extend up as high as the soil on the exterior wall. [See Figure 1] To accomplish this the foundations were installed by removing a strip of the floor slab around the perimeter by saw cutting. Then foundations were then carefully excavated next to the existing wall foundations. The foundation of the cantilever retaining were placed next to the existing foundations and were brought flush with the floor so that it served as a new perimeter strip of floor slab in the basement. A reinforced concrete cantilevered retaining wall from was constructed immediately in front of the rock basement wall. The wall was used as the back form and the concrete was placed in the cavity between the form and the wall. This provided restraint for the existing mortar, filled in any gapes in the rock wall and

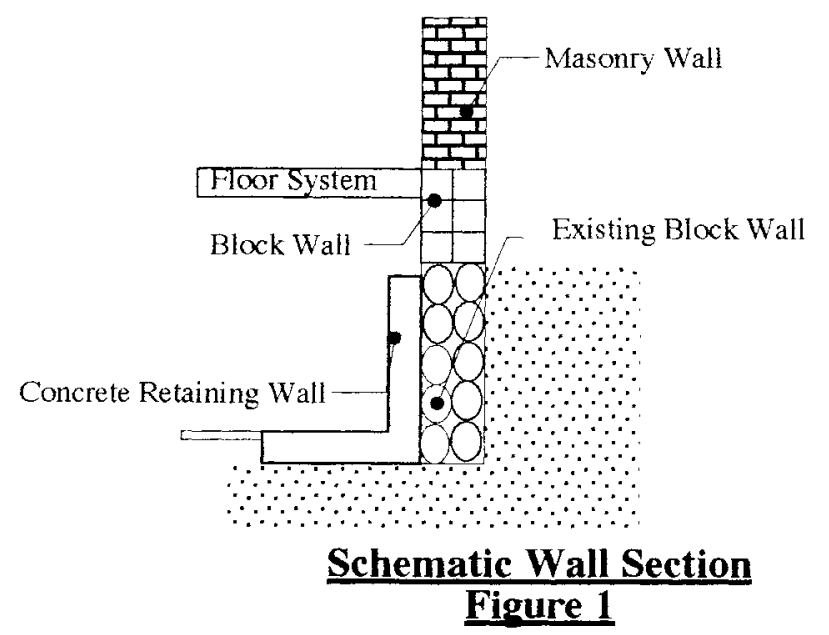


provided additional lateral restraint for the basement wall soil loads. This option examined was the most economical solution and it stabilized the wall very well. The basement served only as a storage area and maintaining the historic character was not a requirement by the owner and architect.

\section{ADDITIONAL LOADS}

The next issue was the additional gravity loads on the structure due to the addition of stage equipment, catwalks, lighting and other elements required for the conversion to a theater building. After a preliminary investigation of the new load requirements, it was decided that an independent load structure would be the best strategy to accommodate them. Several structural configurations were investigated, from a three dimensional truss to a simple frame. The budget restraints were quite sever however so the simplest and most cost effective method was chosen, which was a simple steel frame. This supported a future catwalk and all the lighting and other equipment required.

In order to construct the frame large square steel tube columns were installed from the basement floor through the main floor and up to the roof level of the structure. (See Figure 2). Prefabricated girder trusses were installed along the long building axis column lines. Prefabricated cross trusses spanned the short direction. These trusses which were connected at the columns were also designed to provided partial lateral support in both directions. The frame was designed to carry these lateral forces as well as gravity forces by developing moment resisting connections within the system. This was not required by code however since the structure was there for gravity loads and it was very inexpensive to add the lateral capability. The result was a light airy structure that was unobtrusive on which equipment could be mounted and dismounted very easily and effectively.

In addition to the equipment loads there was a mezzanine area that was added to the East end of the building to serve as a control and lighting booth. The floor structure of the mezzanine was mounted to the columns of the frame. It was easy to connect to the columns, and made for a very economical floor system.

The floor structure over the basement consisted of wood joist and wood beams. The wood beams were over stressed by the new loads and needed to be reinforced. The steel frame, again was used to provide this support. The steel frame columns were installed adjacent to the existing floor columns. This allowed the installation of steel cross beams at the floor level under the existing wood beams. This provided adequate capacity for the new floor loads. Additional small perimeter columns were installed to support the floor joist outside the center column area.

The some of the trusses were failing in the center cruciform area of roof structure. Because of structure of the truss and the limited access in the roof attic, the repair of the failed portion of the trusses would have been a very time consuming and expensive process. As an alternative it was decided to provide the roof support in the locations of the failed truss by using the steel frame below. Columns were installed from the steel frame up to the trusses at locations where distress had occurred. This resulted in a very economical repair to the trusses.

\section{GENERAL DISCUSSION OF SEISMIC ISSUES}

Unreinforced masonry buildings do not respond well structurally in seismic events. They lack most of the components commonly associated with modern reinforced masonry construction designed for seismic regions. The basic requirements for seismic resistance are a load path to ground, roof and floor diaphragms, tension chord ties, positive connections of the floor and roof diaphragms to the walls, and adequate shear walls. The more sever the earthquake, the more the building requires these components to function properly. ${ }^{2}$

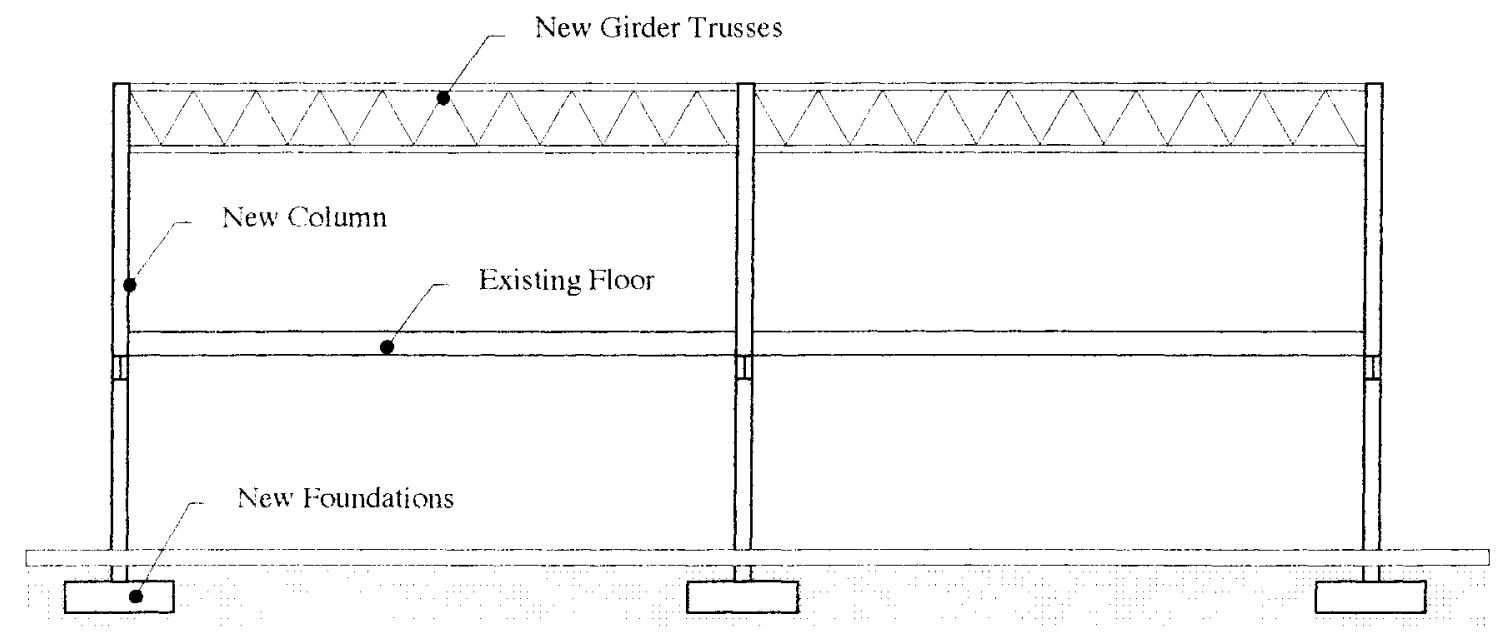

Schematic Frame Elevation Figure 2 
The dilemma in preservation of historic buildings is how to accomplish this task without destroying the historic character of the building. It is very difficult and expensive to bring a unreinforced masonry building up to current seismic standards. Some times it may be impossible to meet both seismic requirements and historic preservation requirements.

The seismic requirements for unreinforced masonry buildings in seismic zones below three are much less than the higher zones, like zones three and four. In seismic zones such as $2 \mathrm{a}$, the UCBC's basic requirement for historic buildings relates to the connecting roof and floors to the walls. This is usually accomplished by adding a connection device such as through anchors, and large plate washers through the wall to the roof and floor system. In the case of this building the walls were tied to the roof. ${ }^{1}$

Besides carrying the new gravity load and some of the lateral forces, the frame served several other functions. It provided a location where connections could be made tie down the roof structure. The roof was a light weight metal tile roof that needed to be tied down for uplift wind loads. In addition the unreinforced masonry walls at the roof level were tied to the frame to provide redundancy for lateral loads. The walls were connected by means of through bolts and plates from the frame to wall, a standard way of developing connections for unreinforced masonry structures. The connector was also tied to the roof diaphragm so there was a double action of an existing roof diaphragm that was partially effective and the frame both resisting the loads from the walls. It was an efficient use of the moment frame and made for a more stable structure with the walls and roof tied to the steel frame.

\section{WALL STRUCTURE}

Some time before the investigation, the basement floor had been flooded by water from a broken main. This resulted in some foundation settlement on the South-West corner of the building, which caused some cracking along the window lines of the upper structure. The Geotechnical Engineer indicated that the settlement would stop if there was no further exposure to water. The repair resorted to using a surface prestressing rod to stabilize and hold the wall in place. Since there was steel super-structure used on the inside for gravity support, A steel prestressing rod on the surface was entirely consistent with the design. The connection was a corner load plate designed with tension rods that connected from the corner through one of the existing walls that served as a tie back. See how this functioned in the enclosed diagram in figure 3 . This served to stabilize the wall from any further cracking. Concrete walks were installed in locations where potential moisture problems might occurred to prevent any further moisture from intruding from outside.

The change of use made the improvement in structure necessary by code. Changing the use to a theater required the internal support structure. The building externally main-

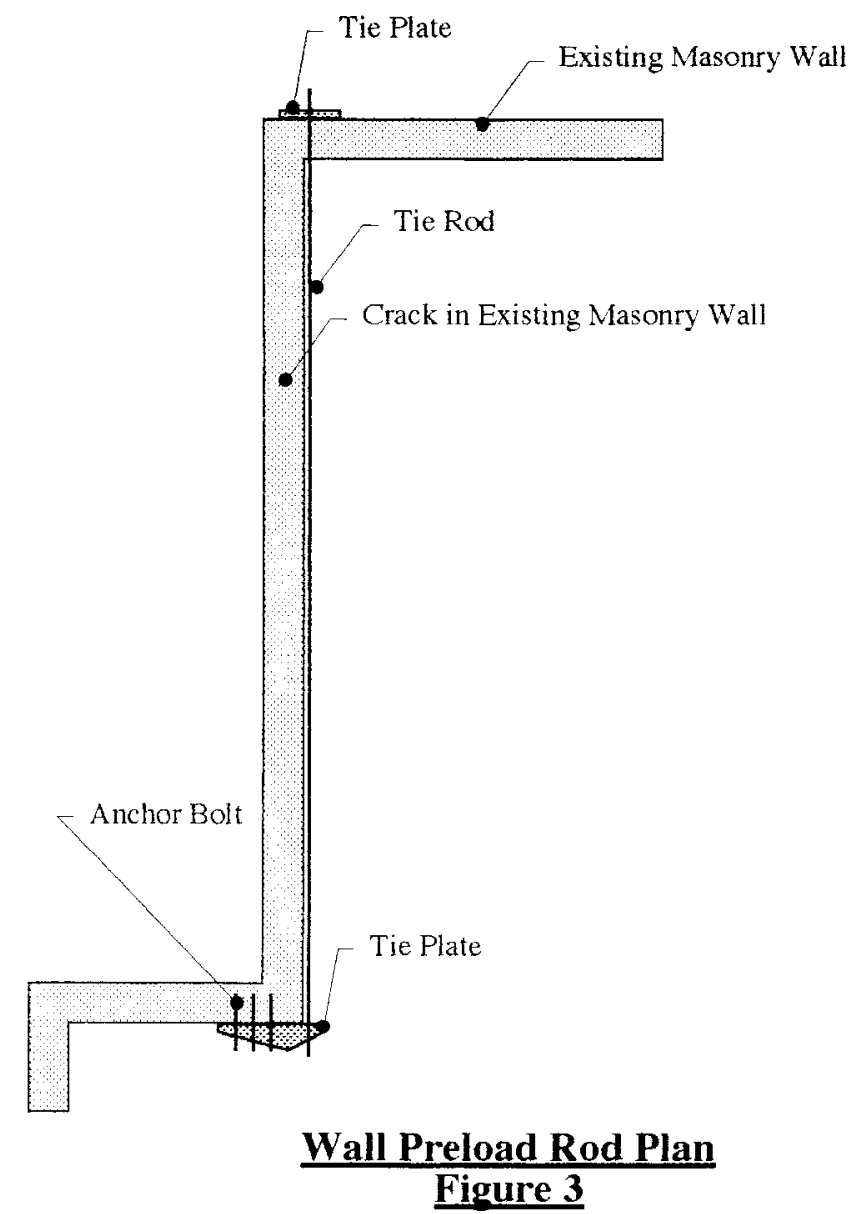

tained its basic visual character within the community. The inside was changed to meet its new use requirements but the old character remained intact and visible past the new internal support structure.

This project provided an example of how the process of revitalizing older structures can be accomplished without the destruction of the historic fabric. The approach of an internal support structure was consistent with the use. Theaters generally have to have a superstructure to support the theater equipment. Be making the structure perform double duty provided an opportunity for a safer building without much intrusion into the historic character of the building. This demonstrates that the renovation of older buildings is economically feasible and historically correct. The building has been very successful and has many art groups now using it on a continuous basis.

\section{BIBLIOGRAPHY}

1 International Conference of Building Officials. Uniform Code for Building Conservation. 1991 Edition 5360 South Workman Mill Road, Whittier, California.

${ }^{2}$ Lagorio, Henry J., Earthquakes, An Architect's Guide to Nonstructural Seismic Hazards, John Wiley \& Sons, Inc. New York, Pages 60-27, \& 83-137 